\title{
A EXTENSÃO E SEU PAPEL EMANCIPATÓRIO: ESTUDO DE CASO “CARTOGRAFIA SOCIOCULTURAL" EM VIÇOSA, MG
}

\author{
Luis Gustavo Ferreira Cabral ${ }^{1}$ \\ Amélia Carla Sobrinho Bifano ${ }^{2}$
}

\begin{abstract}
RESUMO: Este trabalho visa realizar um estudo sobre a extensão universitária é tratada no Brasil, por meio da análise do projeto "Cartografia Sociocultural”, realizado pelo Departamento de Economia Doméstica da Universidade Federal de Viçosa (UFV). Para tanto, remonta-se à instauração dos primeiros projetos de extensão no Brasil, como os modelos Land Grant de universidade, assim como o Centro Rural Universitário de Treinamento e Ação Comunitária (CRUTAC) e o Projeto Rondon, a evolução da extensão ao longo do tempo, seu objetivo e os moldes atuais, além do estudo de caso do projeto "Cartografia Sociocultural", por meio da metodologia da pesquisa-ação, envolvendo a população alvo do estudo aos trabalhos realizados e chegando a resultados concretos de suporte à decisão por parte da população estudada.
\end{abstract}

PALAVRAS-CHAVE: Extensão universitária. Cartografia social. Conhecimento emancipador.

University extension and their emancipatory role: "Cartografia Sociocultural" study case in Viçosa, $M G$

\begin{abstract}
This work seeks to achieve a study about how the university extension is discussed in Brazil through the "Cartografia Sociocultural" project analysis, realized by Domestic Economy Department of Universidade Federal de Viçosa (UFV). For such achievement, we have been look back to the firsts instauration extensions projects in Brazil, like the Land Grant university models, the CRUTAC and the Rondon Project, the extension evolution over the years, its objective and its actual models, beyond the study case of the Cartografia Sociocultural project, through research-action methodology, involving the target population of study with the works realized, reaching to visible results that will serve to support the population's decisions.
\end{abstract}

KEYWORDS: Extension university. Socio cartography. Emancipatory knowledge.

\section{INTRODUÇÃO}

Chegamos ao século XXI e a capacidade técnica e tecnológica cresce a uma velocidade assustadora, em uma era chamada tecnocrata ou tecnicista, na qual a informação e as transformações são cada vez mais rápidas, a acumulação de capital nunca foi tão grande, assim como a desigualdade de distribuição desse capital.

\footnotetext{
Graduando em Geografia pela Universidade Federal de Viçosa, estagiário da Unidade Interdisciplinar de Estudos em Desenvolvimento Humano e Social (luis.cabral@ufv.br).

2 Doutora em Engenharia de Produção pela Universidade de São Paulo, com período sanduíche na França, no Conservatoire National des Arts et Métiers, professora adjunta na Universidade Federal de Viçosa, coordenadora da Unidade Interdisciplinar de Estudos em Desenvolvimento Humano e Social (abifano@ufv.br).
} 
De acordo com Santos (2000), nunca existiram, como nas últimas décadas, tantas condições técnicas e tecnológicas para a promoção da igualdade entre os seres humanos, seja no âmbito econômico, seja no âmbito social. No entanto, o que presenciamos é o uso dessas condições para o distanciamento entre a classe dominante, portadora das condições técnicas e do capital, e a classe subalterna, explorada e à margem das inovações técnicas e científicas.

A universidade tem importante papel no desenvolvimento do meio técnico-científico-informacional (SANTOS, 2000), desenvolvido pelo e voltado para o modelo capitalista, controlador de inúmeras relações entre pessoas, empresas e estados. É, também, papel da universidade promover a difusão do conhecimento e da técnica gerada para toda a sociedade, sem restrição de classe, promovendo, principalmente para as classes mais baixas, um conhecimento-emancipador, tratado por Santos (2001) e considerado como o conhecimento que induz a pensar nas consequências dos próprios atos, tendo, com a sociedade, uma relação sujeito-sujeito, promovendo a interação e a participação da comunidade em geral em projetos e pesquisas. Este modelo de conhecimento contraria o senso comum gerado em torno da ciência moderna, que apesar de criar inovações e promover o desenvolvimento, priva boa parte da sociedade de participar dessa construção de modernidade.

A esfera da universidade que tem como função integrá-la à sociedade é a extensão, que, juntamente com a pesquisa e o ensino, forma a tríade que sustenta a legitimidade da universidade. No entanto, a discrepância de investimento e valorização entre a extensão e as demais esferas é grande e nítida.

Para entendermos melhor a razão desta discrepância e qual, exatamente, é a função da extensão universitária no Brasil, devemos nos remeter ao início de sua implantação no país, o contexto político da época e os modelos extensionistas inicialmente implantados, sua evolução e como a extensão vem se configurando nas últimas décadas.

O primeiro projeto de extensão no Brasil seguiu os moldes da extensão rural aplicada na Escola Superior de Agricultura e Veterinária (ESAV), atual Universidade Federal de Viçosa, na cidade de Viçosa-MG, implantada pelo presidente Arthur Bernardes, em 1926, seguindo os padrões norte-americanos das universidades Land Grant, tendo a extensão, a forma de assistencialismo aos agricultores da região, traduzindo-se na realização da semana do fazendeiro, que acontece todos os anos na cidade de Viçosa-MG, desde 1929 até os dias atuais.

Este modelo norte-americano tem como principal característica, segundo Gurgel (1986), a prestação de serviços ligada exclusivamente ao meio rural, provendo assistência e ensino técnico às famílias que vivem no campo. Deste modo, a extensão nasce no Brasil com a função básica de prestação de serviços técnicos gerais relacionados ao campo.

Gurgel (1986) salienta que, a partir da década de 1950, o modelo norte-americano tem grande difusão no Brasil, uma vez que o Estado o considerava um instrumento eficaz de apoio a quem vivia nas zonas rurais (e que ainda representava a maioria da população brasileira). Assim sendo, a prestação de serviços realizada pela extensão fazia parecer ao agricultor que este participava do processo de mudança, quando, na verdade, a prestação de serviços mascarava a falta de políticas mais específicas para as áreas rurais, buscando garantir a alienação da população perante estas questões políticas, mantendo a ordem e o consenso no meio rural. 
A extensão sofreu grande impacto a partir da recuperação das Universidades Populares, criada no início do século XX com uma filosofia, modificada, no final dos anos de 1950, pela ação do movimento estudantil a partir da criação da Lei de Diretrizes e Bases da Educação (LDB/1958). Criada dentro da política desenvolvimentista do presidente Juscelino Kubitscheck, de acordo com Gurgel (1986), a Universidade Popular fazia parte da superestrutura estatal que deveria servir como impulso para a evolução social, aumentando o acesso ao conhecimento e subsidiando tecnicamente, não de forma paternalista, a população mais pobre, principalmente na busca por seus direitos. Em vez disso, a Universidade Popular abrangia uma parcela da sociedade alienada e muitas vezes desinteressada, falhando assim em sua missão profissional, cultural e social.

Outras tentativas de implantação de projetos de extensão, nos moldes assistencialistas, também aconteceram no decorrer da década de 1960, como, por exemplo, o CRUTAC (Centro Rural Universitário de Treinamento e Ação Comunitária) e o Projeto Rondon, que é realizado até os dias atuais. Esses projetos eram coordenados pela CODAE (Coordenação de Atividades de Extensão), que surgiu da união MEC/Minter e pregava a ideia de extensão como uma função da universidade de levar suas atividades sob a forma de cursos e/ou serviços especiais a locais desprovidos de recursos que possibilitassem a implantação de escolas técnicas e universidades.

Na visão de Freire (1979), esse modelo de extensão, algumas vezes, pode ser interpretado como uma forma dominadora, sendo a população um mero receptor, uma vez que o lado que produz e repassa o conhecimento (universidade) tem uma visão de mundo e uma condição de vida distinta de quem "recebe" o conhecimento (população), dando uma impressão de superioridade, suprimindo o conhecimento não formal possuído pela população estudada. O pedagogo aponta a comunicação e a transmissão como solução desse problema, no qual a extensão deveria ter como base de trabalho algumas palavras chaves como: Retroalimentação (no sentido de ida e volta de informações e conhecimento entre universidade e sociedade), Integração (da extensão com a pesquisa, a educação e principalmente a sociedade), Abertura (de ideias e formas de ação), Equilíbrio (entre conhecimento formal e informal), Projeção (de ações conjuntas entre universidade e sociedade).

A extensão, neste sentido, é um elo entre universidade e sociedade. Gonçalves (1976) aponta a extensão como a forma natural de integração entre universidade e sociedade e talvez a única forma de se avaliar a representatividade das ações da universidade na sociedade, assim como as respostas da sociedade e suas repercussões na universidade.

Algumas transformações foram notadas na extensão ao longo do século XX, como a lenta transição e a metamorfose entre os modelos assistencialistas, amplamente difundidos anteriormente, e o modelo comunicativo-transmissor proposto por Paulo Freire. Ainda assim, a diferença de investimento e de reconhecimento entre extensão, pesquisa e ensino é gritante, principalmente no que diz respeito ao capital privado, fruto do processo capitalista de acumulação, que tem na pesquisa seu único foco de investimento, esperando um retorno por meio de novas tecnologias e privando boa parte da sociedade do conhecimento produzido na universidade.

Em meio a essa nova ordem mundial, extremamente excludente e autoritária, a extensão universitária possui, de acordo com Rodrigues (1999), a função de combater as desigualdades por meio de ações mais humanistas, transformando o conhecimento produzido dentro da universidade 
em uma forma de apoio a população mais necessitada de uma forma igualitária e cidadã, possuindo o intuito de diminuir a lacuna entre as camadas extremas da sociedade.

Essa busca por uma maior participação popular nos trabalhos de extensão é um dos objetivos do projeto "Cartografia Sociocultural", nos qual se utiliza como base de ação, principalmente, os conceitos de Retroalimentação, Abertura e Equilíbrio, utilizados por Freire (1979), em um processo conjunto com a população da área alvo do estudo, na busca de melhorias na qualidade de vida desta mesma população. A forma de ação e a metodologia utilizada no projeto visam servir de base para seu aperfeiçoamento e possível replicação, tanto na UFV como em outras universidades.

De acordo com o discorrido acima, a extensão, em uma dinâmica atual, tem como uma de suas principais funções transformar o conhecimento produzido na universidade em apoio à população mais necessitada, de uma forma igualitária e cidadã.

Assim, este trabalho pretende analisar como a extensão universitária desenvolveu-se ao longo dos anos, seus conceitos e suas formas de aplicação, bem como o modelo utilizado pelo projeto "Cartografia Sociocultural", na cidade de Viçosa-MG, sua metodologia e parte de seus resultados, observando como estes resultados podem influir na vida da comunidade estudada.

\section{OBJETIVOS}

O presente texto tem como objetivo analisar o projeto "Cartografia Sociocultural" como ação de extensão e sua utilização no método da pesquisa-ação, promovendo a participação da população envolvida no estudo, descaracterizando o viés essencialmente assistencialista da extensão e trabalhando-o como uma ação conjunta entre universidade e sociedade.

Além disso, buscamos apresentar o modelo da pesquisa-ação na extensão; analisar o envolvimento da comunidade no trabalho desenvolvido e identificar quais ações foram, ou pretendem ser, realizadas pelo projeto e como elas auxiliam na melhoria das condições no bairro.

\section{METODOLOGIA}

Em meio às mudanças existentes em relação à extensão, a metodologia utilizada nas intervenções do projeto "Cartografia Sociocultural”, no Bairro Santo Antônio em Viçosa-MG, busca englobar a população foco do estudo à própria pesquisa, por meio da técnica da pesquisa-ação, proposta por Thiollent (2005). Este tipo de intervenção propicia estudar a realidade na qual ela se encontra, por meio de conversas e discussões com os próprios sujeitos que a constroem.

A utilização deste modelo de técnica procura desvincular o projeto de um caráter estritamente assistencialista de intervenção, envolvendo a população e o seu saber popular nas ações a serem realizadas. Dessa forma, facilita-se a troca de informações entre população e universidade na 
análise das condições de vida dessa população, tendo a universidade uma importância idêntica à da população, promovendo uma relação não autoritária. Busca-se, também, estimular uma consciência de participação e cidadania nos moradores envolvidos no projeto, no qual o resultado esperado é um crescimento do interesse desses moradores na participação política nas discussões que envolvem decisões referentes ao seu lugar de moradia.

Neste modelo de extensão, o projeto iniciou seu trabalho buscando formar uma ligação com os moradores do bairro estudado. Para isso, foram identificadas as lideranças formais, como os vereadores que moram no bairro, as pessoas constituintes da associação de moradores, assim como as informais, sendo estas geralmente pessoas mais idosas, indicadas pelos próprios moradores, que moravam ali há muito tempo ou tinham uma ligação maior com o bairro. Por meio destas lideranças, o trabalho foi divulgado para o restante da população habitante do bairro e foi realizada a primeira reunião com os moradores que se interessaram em participar do projeto. Nesta reunião, foram levantados as principais preocupações e anseios da população em relação às condições do bairro e da própria condição de vida dos moradores.

A participação dos moradores, desde a primeira reunião, tem sua aplicação ligada ao objetivo de criar o sentimento de importância para e com projeto, fazendo com que esses moradores empenhemse em suas atividades, aguçando a união e a participação da comunidade. O mapa de acessibilidade, mostrado no item "Resultados e Discussões", por exemplo, é fruto do empenho da comunidade no levantamento dos indicadores (e a importância de cada um desses) necessários para sua criação, que aliado ao suporte técnico dado pelos integrantes do projeto, teve como resultado um produto que pode ser usado pela própria comunidade na busca de melhorias nas condições de acessibilidade.

Essa troca de informações entre comunidade e universidade é um dos principais focos desta metodologia, sendo intrínseca às ações desenvolvidas e essenciais para a aplicação desse molde de projeto.

\section{RESULTADOS E DISCUSSÃO}

O projeto "Cartografia Sociocultural" possui uma equipe interdisciplinar e trabalha em parceria com outros projetos dentro da Unidade Interdisciplinar de Estudos em Desenvolvimento Humano e Social (UNIEDHS). Os trabalhos realizados pela UNIEDHS são desenvolvidos sempre em consonância com a população habitante de determinada área estudada e sempre em resposta aos anseios e problemas dessa mesma população.

Um dos problemas encontrados na cidade de Viçosa, e também no Bairro Santo Antônio, é a falta de identificação por parte de seus moradores com o lugar onde moram, devido, principalmente, ao fato de a cidade possuir uma caracterização de cidade universitária, sendo muito grande sua população flutuante e muito curto o tempo que boa parte dessa população permanece na cidade, causando esse distanciamento quanto à história da cidade e do bairro.

Assim sendo, foi proposta a criação de uma cartilha contendo a história do bairro, desde sua criação 
até os dias atuais, tratando dos principais acontecimentos e principais sujeitos que contribuíram e contribuem com o bairro. Essa cartilha foi constituída por elementos históricos formais, encontrados em livros, revistas, artigos, sites etc., e por relatos e fotografias disponibilizadas pelos moradores mais antigos. A cartilha visa divulgar a história do Bairro Santo Antônio, despertando em seus moradores um sentimento de pertencimento ao lugar para, assim, atribuírem mais valor ao bairro onde moram, e, consequentemente, aguçar seu lado cidadão participativo, aumentando a vontade para buscar melhorias nas condições estruturais do lugar onde vivem, elevando sua qualidade de vida.

Outro exemplo de resposta ao apelo populacional pode ser notado na criação de uma nova metodologia de análise de qualidade de vida, desenvolvida pelos integrantes do projeto, que engloba fatores ambientais a análise comumente utilizada de apenas fatores socioeconômicos que pretendem servir como base na elaboração de políticas setoriais, uma vez que boa parte da população se vê carente quanto a estas políticas públicas.

Um importante produto desta nova metodologia é o mapa de acessibilidade. Para a elaboração do mapa, foi realizada uma classificação das ruas que tem como parâmetro o cumprimento do Decreto $\mathrm{n}^{\circ}$ 5.296, de 2 de dezembro de 2004, que regulamenta a Lei $\mathrm{n}^{\circ} 10.048$, de 8 de novembro de 2000, que prioriza o atendimento às pessoas que especifica, e a Lei $\mathrm{n}^{\circ} 10.098$, de 19 de dezembro de 2000, que estabelece normas gerais e critérios básicos para a promoção da acessibilidade. O Decreto, em seu Capítulo III: Das Condições Gerais da Acessibilidade, dispõe no Art. 8:

Para os fins de acessibilidade, considera-se:

I - acessibilidade: condição para utilização, com segurança e autonomia, total ou assistida, dos espaços, mobiliários e equipamentos urbanos, das edificações, dos serviços de transporte e dos dispositivos, sistemas e meios de comunicação e informação, por pessoa portadora de deficiência ou com mobilidade reduzida (BRASIL, 2004)

E, ainda, no Art. 10:

A concepção e a implantação dos projetos arquitetônicos e urbanísticos devem atender aos princípios do desenho universal, tendo como referências básicas as normas técnicas de acessibilidade da ABNT, a legislação específica e as regras contidas neste Decreto (BRASIL, 2004).

Nestes artigos, fica garantida a utilização, com segurança e autonomia, dos espaços, mobiliários e equipamentos urbanos por qualquer pessoa, inclusive aquelas portadoras de deficiência ou com mobilidade reduzida, como é o caso de idosos e gestantes, considerados na classificação das ruas do bairro, sendo a garantia feita pelo poder público.

A classificação final possui nove tipos, variando entre ÓTIMA, para o cumprimento total da lei, e PÉSSIMA para o total descumprimento da lei. Os tipos de classificações estão descritas abaixo:

- Ótima: oferece total acessibilidade a todo tipo de deficientes (físicos, visuais, auditivos), idosos, gestantes e quaisquer pessoas, em toda a sua extensão. 
- Boa: oferece grande acessibilidade a todo tipo de deficientes (físicos, visuais, auditivos), idosos, gestantes e quaisquer pessoas, na maior parte de sua extensão.

- Regular: oferece parcial acessibilidade a todo tipo de deficientes (físicos, visuais, auditivos), idosos, gestantes, e quaisquer pessoas, na maior parte de sua extensão.

- Ruim: oferece pouca acessibilidade a todo tipo de deficientes (físicos, visuais, auditivos), idosos, gestantes, e quaisquer pessoas, na maior parte de sua extensão.

- Péssima: não oferece acessibilidade a todo tipo de deficientes (físicos, visuais, auditivos), idosos, gestantes, e quaisquer pessoas, na maior parte de sua extensão.

As variações entre tipos (Péssima - Ruim; Ruim - Regular; Regular - Boa; Boa - Ótima) também foram consideradas no mapeamento.

Para a elaboração do mapa, foi realizada uma classificação em escala likert, na qual foram considerados fatores como calçamento/pavimentação de ruas e calçadas (caso existam), declividade das ruas (sua influência na dificuldade de transitar naquela rua), presença/ausência de degraus e rampas de acesso (e tamanho dos degraus, caso existam), apropriação do espaço público (presença de algum tipo de impedimento físico para o trânsito de pessoas), presença/ausência de facilitadores de circulação como faixas de pedestres e semáforos (levando-se em conta o fluxo de veículos de cada rua). Cada rua foi avaliada segundo esses fatores e receberam nota de 1 a 5 para cada um deles. Realizou-se, posteriormente, uma média ponderada dessas notas, uma vez que alguns fatores foram considerados, pela comunidade, mais importantes que outros para a acessibilidade.

a. Presença/Ausência de Calçadas: existência ou não de calçadas (Peso 2,5).

b. Condições estruturais de ruas e calçadas: tipo de pavimentação das ruas e das calçadas (caso estas existam) e presença/ausência de degraus (tamanho desses, caso existam) e rampas de acesso (Peso 2,5).

c. Apropriação do espaço público: presença ou não de qualquer tipo de estrutura física, como postes de iluminação, árvores, mesas de bar, anúncios ou propagadas etc., que dificultem o trânsito de pedestres pelas vias públicas e calçadas (Peso 1,5).

d. Presença/Ausência de facilitadores de trânsito: existência ou não de recursos que facilitem o trafego de pessoas como faixas de pedestres e semáforos, de acordo com o tráfego de veículos nas ruas (Peso 1,5).

e. Fator físico: influência de fatores físicos, como a declividade, no trânsito de pedestres (Peso 1). 


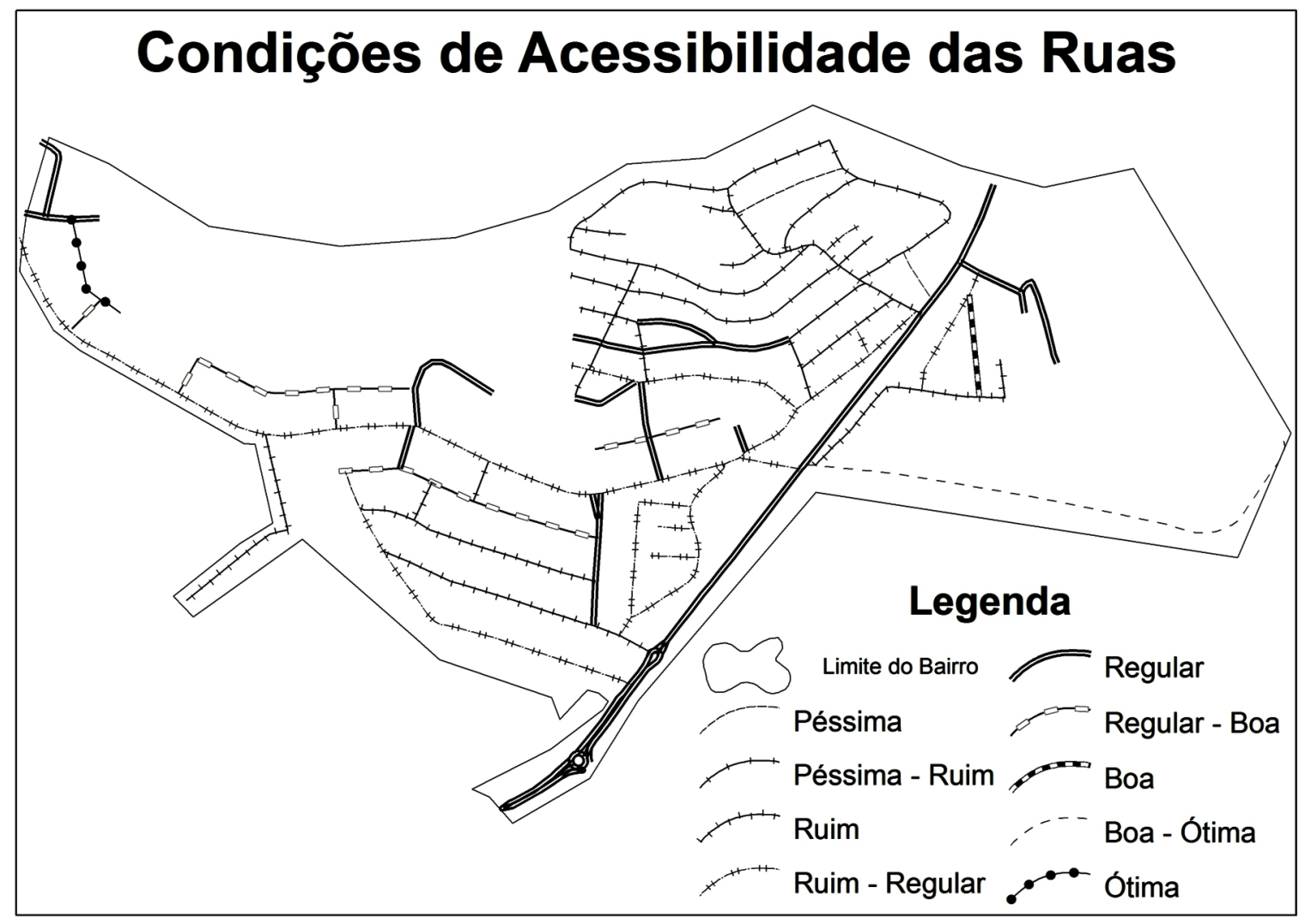

Fonte: Projeto “Cartografia Sociocultural”.

Esta classificação final pode ser considerada um importante instrumento para a população do bairro, pois, por meio de uma base técnica, mostra a precariedade das ruas quanto à acessibilidade, descumprindo, assim, a lei, proporcionando uma ferramenta de argumentação junto aos órgãos competentes na busca por melhorias neste quesito.

Os produtos citados acima compõe uma gama de variadas ações realizadas no projeto "Cartografia Sociocultural”, que possuem esse intuito de troca de informações e saberes na busca de melhorias nas condições de vida da comunidade envolvida.

Todos os resultados, assim como suas análises são repassados e discutidos com os moradores para que eles decidam qual a melhor ação a ser tomada. Neste sentido, vemos um modelo de extensão universitária que visa atender aos princípios da extensão, aliando o conhecimento produzido na universidade ao da população, de um modo simples e que facilita seu entendimento, podendo ser usado na busca por melhorias na qualidade de vida. 


\section{CONSIDERAÇÕES FINAIS}

Apesar do auxilio técnico-científico prestado aos moradores do Bairro Santo Antônio, em Viçosa-MG, a maior contribuição dada pelo projeto "Cartografia Sociocultural" foi a de implantar o método da pesquisa-ação, envolvendo os sujeitos na construção do projeto voltado para eles mesmos, levando a ideia de conhecimento-emancipador em busca de formar uma consciência cultural e cidadã na população do bairro, a fim de que estes criem uma identidade com o lugar onde vivem e busquem melhorias na sua qualidade de vida.

Desse modo, mostra-se o comprometimento do projeto Cartografia Sociocultural na tentativa de atuação dentro de um novo molde de extensão, pregada por autores como Freire (1979) e Gonçalves (1976), de levar experiências de trocas de saberes à população, aliando o saber formal, aprendido na universidade, ao saber informal, aquele não ensinado por meios educacionais, mas que tem, também, grande importância no desenvolvimento social.

\section{REFERÊNCIAS}

BRASIL. Decreto $n^{\circ}$ 5.296, de 2 de dezembro de 2004. Regulamenta as Leis nos 10.048 , de 8 de novembro de 2000, que dá prioridade de atendimento às pessoas que especifica, e 10.098, de 19 de dezembro de 2000, que estabelece normas gerais e critérios básicos para a promoção da acessibilidade das pessoas portadoras de deficiência ou com mobilidade reduzida, e dá outras providências. Disponível em: < http://www.planalto.gov.br/ccivil_03/_ato2004-2006/2004/ decreto/d5296.htm>. Acesso em: 20 maio 2012.

FREIRE, P. Extensão ou comunicação? Rio de Janeiro: Paz e Terra, 1979.

GONÇALVES, N. T. A extensão como uma das funções básicas da universidade. In: Coletânea de documentos sobre extensão universitária. Brasília: DDD/MEC, 1976.

GURGEL, R. M. Extensão universitária: comunicação ou domesticação? São Paulo: Cortez, 1986.

RODRIGUES, M. M. Universidade, extensão e mudanças sociais. Em Extensão, Uberlândia, v. 1, n. 1, p. 41-51, jan./jun. 1999.

SANTOS, B. de S. Pela mão de Alice: o social e o político na pós-modernidade. São Paulo: Cortez, 2001.

SANTOS, M. Por uma outra globalização: do pensamento único à consciência universal. São Paulo: Record, 2000.

THIOLLENT, M. Metodologia da pesquisa-ação. 14. ed. São Paulo: Cortez, 2005.

Submetido em 20 de junho de 2012.

Aprovado em 14 de agosto de 2012. 